\title{
Resident Perceptions of Mosquito Problems Are More Influenced by Landscape Factors than Mosquito Abundance
}

\author{
Jeffrey A. Brown ${ }^{1, *(\mathbb{C}}$, Kelli L. Larson ${ }^{2,3}{ }^{\circledR}$, Susannah B. Lerman ${ }^{4}{ }^{\complement}$, Alexandreana Cocroft ${ }^{5}$ and Sharon J. Hall ${ }^{5}$ \\ 1 Global Institute of Sustainability, Arizona State University, Tempe, AZ 85281, USA \\ 2 School of Geographical Sciences and Urban Planning, Arizona State University, Tempe, AZ 85281, USA; \\ kelli.larson@asu.edu \\ 3 School of Sustainability, Arizona State University, Tempe, AZ 85281, USA \\ 4 United States Department of Agriculture Forest Service, Northern Research Station, Amherst, MA 01003, \\ USA; susannah.b.lerman@usda.gov \\ 5 School of Life Sciences, Arizona State University, Tempe, AZ 85281, USA; acocroft@asu.edu (A.C.); \\ sharonjhall@asu.edu (S.J.H.) \\ * Correspondence: jeff.alexander.brown@gmail.com
}

check for updates

Citation: Brown, J.A.; Larson, K.L.; Lerman, S.B.; Cocroft, A.; Hall, S.J. Resident Perceptions of Mosquito Problems Are More Influenced by Landscape Factors than Mosquito Abundance. Sustainability 2021, 13, 11533. https://doi.org/10.3390/ su132011533

Academic Editors: Michael J. Blum, Dawn Wesson and Amy Lesen

Received: 13 September 2021

Accepted: 14 October 2021

Published: 19 October 2021

Publisher's Note: MDPI stays neutral with regard to jurisdictional claims in published maps and institutional affiliations.

Copyright: (c) 2021 by the authors. Licensee MDPI, Basel, Switzerland. This article is an open access article distributed under the terms and conditions of the Creative Commons Attribution (CC BY) license (https:/ / creativecommons.org/licenses/by/ $4.0 /)$.

\begin{abstract}
Mosquitoes and the pathogens they carry are increasingly common in urban areas throughout the globe. With urban landscapes, the need to manage mosquitoes is driven by the health risks and nuisance complaints associated with mosquitoes. Controlling the number of mosquitoes may reduce the overall risk of disease transmission but may not reduce nuisance complaints. This study focuses on Maricopa County in Arizona, USA, to investigate the relationship between mosquito abundance and landscape-level and sociodemographic factors on resident perceptions of mosquitoes. We used boosted regression trees to compare how mosquito abundance, collected from Maricopa Vector Control, and landscape factors and social factors, assessed through the Phoenix Area Social Survey, influence survey respondents' reporting of mosquitoes as a problem. Results show that the landscape and sociodemographic features play a prominent role in how individuals perceive mosquitoes as a problem; specifically, respondents' perception of their local landscape as messy and the distance to landscape features such as wetlands have more substantial roles in shaping perceptions. This work can highlight how potential mosquito and non-mosquito-related communications and management efforts may improve residents' satisfaction with mosquito control or other wildlife management efforts, which can help inform best practices for vector control agencies.
\end{abstract}

Keywords: mosquitoes; perceptions; vector management; urban landscapes; sociodemographic factors

\section{Introduction}

Mosquitoes and their associated pathogens threaten human health globally. Many diseases once isolated to tropical regions are now more prevalent worldwide [1-3]. Mosquito management has long been a priority for many state and local governments. Still, efforts have increased in recent years to address both novel diseases (e.g., Zika Virus) as well as the spread of diseases to new areas (e.g., Dengue Fever within the United States; [4]), especially from less developed countries of the global South to more developed countries of the global North [5-9]. In particular, climate change is expanding the range of several disease-carrying mosquito species into high-density urban and urbanizing areas [10-12]. Human expansion and urbanization provide novel interactions between humans and mosquitoes that may harbor endemic diseases $[5,13]$. As climate change intensifies and human expansion continues, vector-borne diseases and transmission patterns will also change, potentially increasing the vulnerability of urban residents to current and future disease transmission [11,14]. Continued review of climate change and global health in relation to vector-borne diseases are necessary to manage the ever-changing risks associated with human-mosquito interactions [14]. To best manage mosquito populations in cities, it 
is important to understand the drivers of mosquito distribution and abundance, and how people respond to mosquitoes, and how these human-mosquito interactions may feedback to alter management practices $[6,15,16]$.

Humans and mosquitoes are closely linked, and their co-existence forms a coupled system [17-19]. In urban areas, the high density of humans provides mosquitoes with bloodmeals required to produce eggs contributing to mosquito reproduction $[18,20]$. Urban areas also provide abundant suitable habitats for mosquitoes to lay eggs and for the larva to hatch [21-23]. Urban landscapes tend to have more water added to them than natural landscapes [24], which increases mosquito breeding and survival. For example, urban mosquitoes use anthropogenic items and structures such as discarded tires and flowerpots that hold water and often select these artificial breeding sites over naturally occurring sites [23,25]. Furthermore, artificial water bodies often lack natural mosquito predators. Mosquitoes also benefit from other elements associated with cities, such as the urban heat island $[26,27]$. Since temperatures in urban landscapes tend to be warmer than in the surrounding natural areas, several species of tropical disease-carrying mosquitoes, including Aedes aegypti and Aedes albopictus, have been found in cities that are further north than their expected range [28]. As mosquitoes increase in abundance in urban environments, they pose physical and mental health risks to residents. Combatting these risks through further investigation can identify the contributing factors and possible solutions for reducing urban mosquito abundance.

Mosquitoes such as Aedes albopictus and Aedes aegypti pose health risks by acting as vectors of dangerous and sometimes fatal pathogens such as West Nile Virus and Eastern Equine Encephalitis. However, people perceive even non-disease-carrying mosquitoes as nuisance pests that may affect time spent outdoors [29-31]. Combined, the impact on health and nuisance has led many governmental agencies to focus heavily on controlling mosquitoes, especially in highly populated areas [32,33]. The control of mosquitoes takes various forms, including chemical sprays [34,35], direct biological controls (e.g., placing insectivorous fish in bodies of water to reduce mosquito larvae; [36,37]), and indirect biological controls (e.g., releasing genetically modified mosquitoes resulting in non-viable offspring; [38,39]).

In addition to the varying efficacy of different mosquito control techniques, considering urban resident perceptions of management methods can further improve support for, and subsequently funding of, these methods [40-42]. Support for management is often not directly associated with how effectively the control method reduces the mosquito population, underscoring the importance of understanding public perceptions [43-45]. Some methods may be very effective at reducing mosquito populations, such as the release of genetically modified mosquitoes; however, in the short term, they may be viewed as exacerbating the problem if residents experience higher mosquito encounters $[45,46]$. In contrast, methods that may be less effective in reducing the mosquito population but with clear indications of management actions (e.g., pesticide fogging) may be viewed more positively, as residents feel the problem is being addressed [47,48]. With this in mind, understanding the links between mosquito abundance, mosquito control methods, and public perceptions of mosquitoes as a problem is a key factor in determining residents satisfaction with and potential funding for mosquito management methods. Increased public support of management practices may, in turn, lead to increased willingness to adopt behaviors that reduce mosquito populations and reduce the spread of mosquito-borne disease $[49,50]$.

The number of mosquitoes people experience may not relate to whether they perceive mosquitoes as problematic [30]. Therefore, vector control to reduce the population of mosquitoes might not change an individual's perception of mosquitoes as a nuisance. Instead, other factors such as individuals' sociodemographics and their perceptions of local landscapes may influence perceptions of mosquitoes as a nuisance $[23,51,52]$. For example, individuals who have experiences with mosquito-borne diseases may be more likely to perceive mosquitoes as a problem [53,54]. Additionally, individuals who spend less time 
outdoors or do not interact with nature may also be less aware of mosquitoes around them or less concerned about mosquito control [55]. Further, perception of nuisance species may be linked to landscape characteristics, and the presence of specific features such as vacant lots or garbage may relate to perceived increases in pest populations [56,57]. As such, control agencies and scientists can consider more than just mosquito abundance when assessing how to reduce mosquito populations and whether these methods are necessary or effective at reducing perceptions of mosquitoes as a nuisance.

In the Phoenix metropolitan area, and cities worldwide, control of mosquitoes by government agencies (e.g., Maricopa County-Environmental Services Vector Control for Mosquito Management) is performed in part as a response to residents' complaint calls [58]. Maricopa County Vector Control, the government agency that helps control mosquito populations within metro Phoenix, monitors mosquitoes with a network of traps deployed throughout the metro region for routine monitoring and deploys traps in response to the residents' complaints. The agency then aims to reduce mosquito populations using chemical insecticides as well as by introducing insectivorous fish into areas of standing water when appropriate (Arizona Department of Health and Services 2021). Although the actions of Maricopa County Vector Control often successfully reduce the number of mosquitoes within an area, they do not always reduce the complaints residents make about mosquitoes in their area (County Vector Control, 2020). This mismatch between mosquito control actions and residents' complaints to Vector Control highlights a potential inconsistency between how residents perceive mosquitoes as a problem and mosquito abundance.

In this study, we investigated the relationship between mosquito abundance and other landscape-level and sociodemographic factors on residents' perceptions of mosquito problems around their homes. We investigate the extent to which mosquito abundance relates to resident perceptions of mosquitos as a problem around their home, along with local landscape features and perceptions of them, as well as sociodemographic attributes of nearby residents. Our analysis combines mosquito abundance data and spatial variables that capture various landscape features (e.g., natural and desert vegetation and standing water and ephemeral wetlands) and integrates survey data that capture perceptions of mosquitos and local landscapes as well as demographic attributes of residents.

\section{Materials and Methods}

\subsection{Study Area}

Maricopa County is in the Sonoran Desert in Arizona, a state in the southwestern United States. Within Maricopa County, Phoenix and surrounding municipalities compose the fourth largest metropolitan area in the USA, with approximately 5 million residents. The racial and ethnic makeup of the metro area is primarily White $(58.7 \%)$ and Latinx (29.5\%), as well as Black, Asian, and Native American (10\% combined; United States Census Bureau, 2020). The area was originally settled by Hohokam people until around $1450 \mathrm{AD}$, and subsequently, agriculture was greatly expanded by Anglo settlers in the 1800s [59]. Much agricultural land has been converted to urban and residential land, which now dominates the region, but active agriculture remains throughout the region [60]. Although it is situated in a desert, the Phoenix metropolitan area is often classified as an oasis, largely due to irrigation from the Salt and Verde Rivers [61]. In addition to irrigated agriculture, many private and public parcels are landscaped with irrigated lawns, and the metro Phoenix area contains more than 1400 artificial bodies of water [62]. Although grassy landscapes still pervade the region, in recent years, many homes turned to xeric landscaping, which utilizes drought-tolerant and low-water-use plants along with gravel groundcover [63]. On the region's fringes, there are many areas of undeveloped Sonoran Desert, and within the region, several large desert preserves also exist.

Within the study area, we focused on 12 well-studied neighborhoods where residents have been repeatedly surveyed as a part of the Phoenix Area Social Survey, a principal dataset within the Central Arizona-Phoenix Long Term Ecological Research project (CAP LTER). These 12 neighborhoods, delineated by Census Block Groups, were strategically 
chosen to target residents in low-to-high income areas. The neighborhoods span central, suburban, and exurban locations and are in proximity to diverse urban ecological infrastructures (UEI) such as community parks, canals, and desert preserves (Figure 1). We include UEI in our analysis since varying types of infrastructure have differential impacts on ecosystem services that impact human well-being [64]. Recent research shows that resident perceptions of biocultural disservices, such as messy-looking landscapes that attract pests, are linked to proximity to specific UEI, including vacant land, cropland, and the mostly ephemeral Salt River Channel [57].
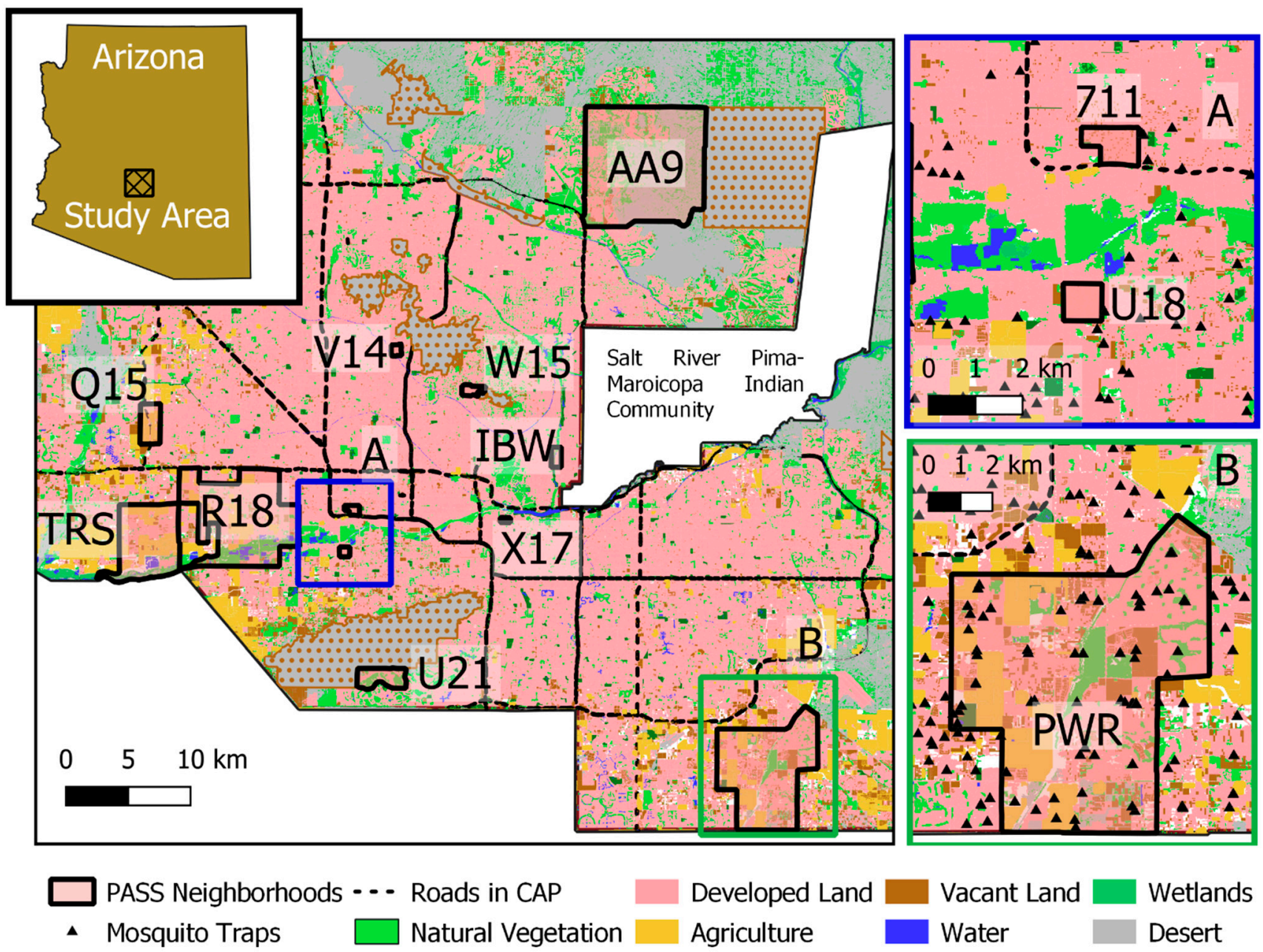

Figure 1. The 12 study neighborhoods are located across the Phoenix Metropolitan Area in Arizona, US. Three neighborhoods, 711, U18 (in box A, highlighted in blue), and PWR (box B, highlighted in green) are highlighted to show landscape features within the neighborhoods as well as the locations of mosquito traps (triangles).

\subsection{Mosquito Abundance}

We estimated mosquito abundance using data from Maricopa County Vector Control (MCVC), which assesses mosquito populations and monitors for disease from $>800$ mosquito traps a week throughout Maricopa County continuously over the year. While there is some variation between trap design, all traps use $\mathrm{CO}_{2}$ lures and contrasting colors to attract mosquitoes with similar efficacy across design types [65,66]. MCVC divides the region into a grid with traps within each grid square throughout the county ("routine traps"). MCVC regularly rotates routine traps to sample each grid for approximately the same number of trap days throughout the year. In addition to these routine traps, MCVC also places traps in locations when residents complain about mosquito problems ("complaints traps") to increase the likelihood of detecting mosquito-borne disease. MCVC also places traps in areas they perceive may serve as mosquito breeding grounds; however, all traps are used to 
monitor mosquito populations, not control them. Thus, the number of traps likely does not influence the underlying population of mosquitoes but instead increases the probability of detecting diseases [65]. Routine traps were active for on average for 45.3 days a year (SD 11.97) and complaints traps were active for 1-9 days, with most (84\%) active for only one day. In total, we assessed mosquito abundance from 109 mosquito traps across three years (2016-2018). In our analysis, we did not differentiate between complaint traps and routine traps as there was no significant difference in the average number of mosquitoes captured per trap day between these two trap types $(t$-test, $p=0.44)$. The years were chosen to coincide with the 2017 survey data we analyzed, as described below.

To estimate the average number of mosquitoes an individual survey respondent may have encountered around their home over the study period, we first identified all traps within $1 \mathrm{~km}$ of a survey respondent. We selected a $1 \mathrm{~km}$ radius to reflect both the average distance that PASS survey respondents identified as "their neighborhood" as well as flight distances of focal mosquito species in patchy urban environments [67-70]. Since the length traps were deployed varied, we calculated the average number of mosquitoes per trap, per trap day, and then averaged these values across all traps within $1 \mathrm{~km}$ of a respondent. We followed this method for 2016, 2017, and 2018 and then averaged this value to calculate a single number to serve as a proxy representing the number of mosquitoes a respondent may experience around their home.

\subsection{Environmental Variables}

Our approach to assessing environmental features of local landscapes in relation to survey respondents followed the UEI approach-developed by Brown et al. [57,71] following Childers et al. [64] —encompassing a variety of terrestrial (green), aquatic (blue), and ephemeral (turquoise) infrastructure. Terrestrial UEI includes agricultural land, community parks, desert preserves, and other features that support ecological function; aquatic UEI includes lakes and other water bodies, including canals that are permanent year-round, and ephemeral wetlands.

Using QGIS (version 3.8.3, 2021), we measured the distance from each survey respondent to various environmental features based on data from the National Agricultural Image Program (NAIP) and the USGS National Land Cover Database (NLCD). Data for the location and distribution of water, agricultural land, developed areas, and natural vegetation came from Zhang and $\mathrm{Li}$ [72], who identified land-use features using $30 \mathrm{~m}$ resolution imagery from NAIP with an overall accuracy of $92.1 \%$. Wetlands were identified using the NLCD and were also classified using $30 \mathrm{~m}$ resolution imagery with an accuracy of $89 \%$ [73]. We identified desert preserves, classified as large natural areas set aside for the preservation of nature and beauty, using municipal records from the Maricopa Association of Governments (azmag.gov, accessed March 2021). Lastly, we identified vacant land and parcels using data from Smith et al. ([74]; $1 \mathrm{~m}$ resolution imagery from NAIP with $90 \%$ accuracy).

For each survey respondent, we calculated the distance (in $\mathrm{km}$ ) to the nearest permanent body of water, wetland, agricultural land, desert preserve, and the amount (in $\mathrm{km}^{2}$ ) of developed area and natural vegetation. These environmental features may influence mosquito populations, especially agricultural lands and wetlands $[75,76]$. Residents in nearby neighborhoods may also perceive these features negatively, which may lead them to report a higher presence of pests, perhaps due to more general dissatisfaction with their neighborhoods [57].

\subsection{Social Variables}

We assessed social factors related to residents in 12 neighborhoods using the 2017 Phoenix Area Social Survey (PASS, [69]), a longitudinal survey effort conducted as a part of the CAP LTER. The survey was sent to 1400 addresses between May through September of 2017; 188 addresses represented households that responded to a previous PASS (2011), and the other 1212 surveys were randomly drawn from addresses provided 
by the Marketing Systems Group, which come from the U.S. Postal Service's Delivery Sequence Files. The University of Wisconsin survey lab administered the questionnaires to households via four-wave mailing, including three full mailings of questionnaires and a reminder postcard sent in-between mailings [69]. Individuals could request a Spanish version with a postage-paid postcard. To increase participation, we sent a $\$ 5$ incentive with the initial mailing of the questionnaire. Upon completion, respondents received an additional $\$ 5-\$ 40$ to bolster survey completion rates (see Smith et al. 2020 for details [77]). A total of $39.4 \%$ of contacted households responded for a total of 496 completed surveys. However, we only included respondents who lived within $1 \mathrm{~km}$ of at least on mosquito trap to ensure mosquito abundance could be linked to survey responses $(n=439)$. Responses were distributed across all twelve neighborhoods (average 37 responses per neighborhood, $\min 19$, max 60). This response rate was representative of the size and population of each study neighborhood [69]. From the questionnaire, we evaluated variables reflecting local mosquito problems, flooding, and perceptions of the local landscapes as messy or natural looking, in addition to including basic sociodemographic characteristics.

Our primary variable of interest from PASS investigated how respondents perceived mosquitoes as problematic around their homes. Specifically, the question asked, "To what extent are mosquitoes a problem for you at your current home?" Answers ranged across a five-point scale, from 1, "not a problem", to 5, "a very big problem". Although the wording of the question states "home", the broader context of this section of the survey contextualizes the home as not just the physical indoor spaces of a residence but also outdoor spaces including yards and patios. We also used PASS data to assess whether individuals perceived their landscapes as likely to flood, since urban landscapes with more water are more likely to provide habitat for mosquitoes [78]. If residents perceive areas as flood-prone, they may perceive these areas as more likely to have mosquitoes. Perception of local flooding was estimated as the maximum value among a set of five questions that asked whether individuals disagreed or agreed with statements related to elements of their neighborhoods flooding, including streets, parks, or nearby canals. We selected the maximum value because we wish to capture if any nearby features flood as opposed to if specific features (e.g., parks versus neighbors' yards) flood. A third survey variable captured perceptions about the messiness of local landscapes in residents neighborhoods. We include this variable since messy areas are associated with an increased belief that a landscape is likely to attract pests [57], and areas with higher amounts of trash (such as vacant lots) can also increase mosquito abundance [22,23]. For messiness, we assessed perceptions along a five-point scale of strongly disagree to strongly agree that "the environment of your neighborhood looks messy". We also measured how natural-looking residents perceived their neighborhoods to be, measured on a five-point scale of strongly disagree to strongly agree that "the environment of your neighborhood looks natural".

Finally, we also used PASS data to capture demographic factors of residents, including gender, income level, level of education, and age. We coded gender on a binary scale with 0 as male and 1 as female. Gender can influence perceptions of risk [79], which may, in turn, influence perceptions of mosquitoes as a health problem or an area as more pestprone [80,81]. Generally, women tend to express more concern over local environmental risks compared to men [82]. We assessed income on an 11-point scale in $\$ 200,000$ increments, from $\$ 20,000$ to over $\$ 200,000$. We included income in the analysis as landscape changes may be cost-prohibitive and thus people with higher income may have more control over their local landscapes, which might influence their perceived control over local mosquito populations and wildlife in general $[16,83]$. We measured education on a 7 -point scale, from completion of grades 1-8 to the attainment of a graduate or professional degree. We included education in our investigation as knowledge of mosquito-borne disease as well as how mosquitoes breed and reproduce may shape perceptions of mosquitoes as problematic within a landscape $[6,84]$. Another factor included was where or not individuals identified as LatinX. We included LatinX identity as our study area has many LatinX individuals (U.S. Census 2020). Lastly, we included respondent age, as many mosquito-related diseases 
are more severe for individuals who are older, and thus older individuals may be more concerned about mosquitoes around their homes $[85,86]$.

\subsection{Boosted Regression Tree}

In this study, we asked how a suite of landscape and social factors, as well as actual mosquito abundance, are related to resident perceptions of mosquitoes as problematic. We used boosted regression trees (BRT) for our analyses, as they incorporate the advantages of tree-based models in handling different types of predictor variables and can capture non-linear relationships that are less easily measured with generalized linear-models or generalized additive models [87-89]. The tree-based approach of BRTs also clearly identifies and weighs variables against one another, allowing us to understand the effects of individual predictors on the dependent variable, but also the relative importance of predictors on the dependent variable when compared to all other variables in the model $[89,90]$. Additionally, some variables in our model are weakly correlated (Pearson correlation coefficient $<0.7$, e.g., mosquito abundance and distance to agriculture: $r=0.14$; mosquito abundance and distance to wetlands: $r=0.05$ ), and boosted regression trees reduce the influence of collinearity by running multiple iterations and injecting randomness $[89,91]$. Finally, as BRTs are generated using randomized subsamples of the entire dataset, the model limits the influence of potential spatial autocorrelation that may occur within neighborhoods [89].

For our model, we set the dependent variable as the 1-5 ordinal response to the question "To what extent are mosquitoes a problem for you at your current home?". For the predictor variables, we included distance $(\mathrm{km})$ to agriculture, water, developed areas, wetlands, natural vegetation, vacant lands, and desert parks. We also included predictor variables of gender, income, education, age, perception of neighborhood flooding, perception of neighborhood messiness, perception of how natural-looking the neighborhood is, and finally, the average number of mosquitoes (log scaled) that were collected within 1-km of a respondent's address. We ran our models in R version 3.6.1 (R Core Team) using the gbm function [92].

\section{Results}

Mosquito trapping effort and abundance varied across neighborhoods. The Power Ranch neighborhood (PWR), one of the largest of all neighborhoods, had the most traps within the smaller neighborhoods U18, V14, and X17 had the fewest (Table 1). Distribution of traps related not only to the size of the neighborhoods (larger neighborhoods contained more unique traps than smaller neighborhoods due to the grid design implemented by MCVC), but smaller neighborhoods had more overlap between the number of traps within $1 \mathrm{~km}$ or respondents (e.g., higher trap density). On average, a respondent lived within 1 $\mathrm{km}$ of 3.1 traps (min 1 trap, max 12 traps). However, although the distribution of traps related to neighborhood size, the abundance of mosquitoes did not. X17, one of the smallest neighborhoods, contained the second-highest average mosquito abundance. The average respondent was exposed to 89 mosquitoes per year with $1 \mathrm{~km}$ of their home with a minimum of 0 mosquitoes and a maximum of 3193 mosquitoes. Mosquitoes were distributed unevenly throughout the study area, likely due to differences in local and neighborhood landscapes; the irrigated, grassy neighborhood of PWR had the highest average number of mosquitoes per trap, and the mostly xeric neighborhood of $U 21$ had the fewest (Table 1). 
Table 1. Information related to both the number of traps within PASS neighborhoods as well as the number of respondents in PASS neighborhoods. The table also shows on average how many traps were located within $1 \mathrm{~km}$ of a respondent and the average number of mosquitoes caught across all traps within $1 \mathrm{~km}$ of a respondent.

\begin{tabular}{ccccc}
\hline Neighborhood & $\begin{array}{c}\text { Total Number of } \\
\text { Unique Traps }\end{array}$ & $\begin{array}{c}\text { Total Number of } \\
\text { Respondents }\end{array}$ & $\begin{array}{c}\text { Average Number of Traps } \\
\text { within 1 km or Respondent } \\
\text { (SD) }\end{array}$ & $\begin{array}{c}\text { Average Number of } \\
\text { Mosquitoes within 1 km of } \\
\text { Respondents (SD) }\end{array}$ \\
\hline 711 & 4 & 17 & $3.05(0.62)$ & $40.84(31.12)$ \\
\hline AA9 & 27 & 26 & $3.77(1.42)$ & $44.68(74.94)$ \\
\hline IBW & 6 & 37 & $2.38(0.59)$ & $35.31(21.26)$ \\
\hline PWR & 45 & 60 & $2.66(1.28)$ & $381.82(580.03)$ \\
\hline Q15 & 8 & 34 & $2.32(1.22)$ & $26.21(26.11)$ \\
\hline R18 & 9 & 26 & $1.42(0.50)$ & $63.71(48.88)$ \\
\hline TRS & 13 & 26 & $1.62(0.70)$ & $110.23(78.44)$ \\
\hline U18 & 3 & 34 & $1.18(0.39)$ & $47.66(42.13)$ \\
\hline U21 & 5 & 52 & $1.34(0.60)$ & $9.63(16.07)$ \\
\hline V14 & 3 & 50 & $1.68(0.55)$ & $64.55(23.53)$ \\
\hline W15 & 13 & 56 & $2.13(1.89)$ & $45.55(26.67)$ \\
\hline X17 & 3 & 39 & $2.28(0.46)$ & $154.00(82.10)$ \\
\hline
\end{tabular}

Results from the boosted regression tree highlighted nine variables that each contributed $>5 \%$ relative influence in predicting whether residents perceived mosquitoes as problematic (Figure 2; per Elith and Hastie [89], variables above a 5\% threshold are important contributors to the dependent variable). Specifically, people under the age of 40 were more likely to perceive mosquitoes as a problem, while those over 50 were less likely to perceive mosquitoes as a problem (12.4\% relative influence, Figure 2, Table A1). Perception of mosquitoes as a problem decreased as the amount of natural vegetation around a respondent's home increased $(12.3 \%)$, with respondents that lived near less than $\sim 1 \mathrm{~km}^{2}$ of natural vegetation more likely to perceive mosquitoes as more problematic and those who lived near more $\sim 1 \mathrm{~km}^{2}$ of natural vegetation perceiving mosquitoes as less problematic. Respondents' perception of their neighborhoods as messy also influenced whether they thought mosquitoes were problematic $(11.4 \%)$. When respondents agreed or strongly agreed their neighborhood was messy, they were more likely to perceive mosquitoes as a problem. However, those who disagreed that mosquitoes were a problem less likely to say mosquitoes were a problem. Additionally, the closer a respondent lived to wetlands $(10.1 \%)$ or agriculture $(8.8 \%)$, the more likely they were to perceive mosquitoes as problematic. The last landscape feature that impacted the perception of mosquitoes as problematic was the amount of vacant land in a respondent's neighborhood with increased vacant land corresponding to increases in perception of mosquitoes as a problem (8.1\%). Finally, as the abundance of mosquitoes around a respondent increased, so did the perception of mosquitos as a problem $(7.2 \%)$, while those with higher incomes $(5.6 \%)$ and higher education $(5.1 \%)$ were less likely to perceive mosquitoes as a problem. 

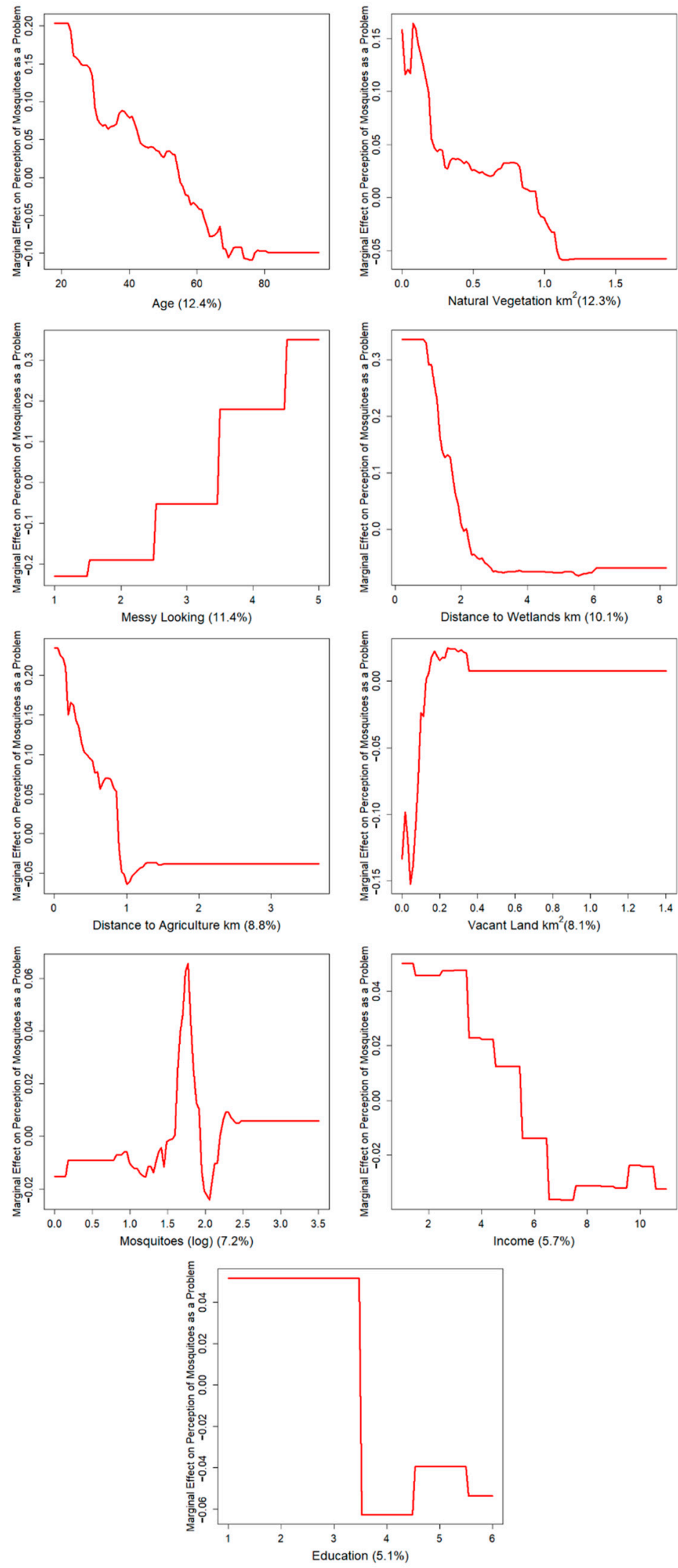

Figure 2. Partial dependency plots for each variable with $>5 \%$ relative influence. When the line is above the dotted line (zero), the variable increases perception of mosquitoes as a problem and below the dotted line decreases perception of mosquitoes as a problem. 


\section{Discussion}

This work highlights the importance of sociodemographic and landscape features on people's perception of wildlife. Specifically, the work illustrates that people's perceptions of nuisance or pest organisms are influenced by more than the abundance of these organisms in residential and urban areas. By understanding how reports of mosquitoes as a problem may vary from underlying distributions of mosquito populations, vector control agencies may be able to implement control measures more precisely and in ways that respond to public concerns. Further, if managers wish to reduce nuisance calls based on perceptions of mosquitoes, they may benefit from addressing factors such as the messiness of local landscapes (e.g., where tires or other materials can harbor water and provide habitat to mosquitoes) as opposed to only spraying chemicals to eradicate mosquitoes. In other words, allocating funding to address the factors associated with perceived problems, as well as the actual occurrence of mosquitos, may be a more effective way to address public concerns while strategically limiting the use of insecticides when the prevalence of mosquitoes is not problematic in specific locations.

Our results match a previous study from France which investigated the perceived risk of mosquito bites and actual exposure to mosquito bites; specifically, Gaillard et al. [30] found that the exposure of individuals to mosquitoes (i.e., the number of mosquitoes captured by scientists within the study region) was not strongly correlated with perceived risk. Our results from metro Phoenix, AZ, emphasize that both perceptions of local landscape and proximity to certain landscape features, as well as sociodemographic factors, are more likely to influence perceptions of mosquito problems than actual mosquito abundance. Given that many people are not able to accurately assess the abundance of wildlife $[93,94]$, we are not surprised that the abundance of mosquitoes is not a major factor influencing perceptions of mosquitoes as problematic. Moreover, these results resonate with risk perception theory, which stresses that perceived risks are highly subjective and not often linked to probabilities of actual risks, such as fatalities $[79,95]$. Overall, the results of this work validate past research while emphasizing that reducing the public perceptions of mosquito problems may require more than active efforts to reduce mosquito populations.

This research also illustrates how the landscape around a resident's home may shape their perceptions and interactions with wildlife. The amount of natural vegetation around a respondent's home and their proximity to agriculture and wetland strongly correlated with residents' perceptions of mosquitoes as problem. All three of these landscapes may shape overall perceptions of a residents' neighborhood either positively or negatively [57]. Although areas with natural vegetation may provide potential breeding areas for mosquitoes [96,97], natural vegetation is often associated with positive ecosystem services which may outweigh negative perceptions $[57,98]$. The possible mismatch between how people perceive landscape features to increase mosquito problems is also highlighted by the influence of wetlands and agriculture on people's perceptions of mosquitoes as a problem. Given that our initial correlation tests during model selection indicated a limited correlation between the distance of a respondent to wetlands and agriculture and mosquito abundance, respondents are likely responding directly to these features. Both agricultural areas and wetlands are often perceived negatively by urban residents and associated with pest species leading to the perception that mosquitoes are more problematic [99-101].

However, in Maricopa County, flood irrigation, a method of watering grass lawns in which the entire lawn is flooded with water, is highly correlated with mosquito abundance $[102,103]$. Local ordinances have restricted this irrigation method unless houses were built before the ordinance date [104]. As such, flood irrigation is often associated with larger, older homes that tend to be in high income areas. If this relationship holds, we expect mosquitoes to be perceived as more problematic in areas with higher income as opposed to in areas near wetlands or agriculture. Instead, the opposite is true. The relationship between income and perceptions of mosquitoes as problematic may also be linked to increases in trash and other refuse that are found in higher abundance in lower income neighborhoods and serve as mosquito breeding sites [16]. 
The influence of income on perceptions of mosquitoes as a problem may also relate to the potential ability to mitigate mosquito-borne diseases through landscaping and features which limit mosquitoes. Although Maricopa County Vector Control will spray in areas where their traps detect disease-carrying mosquitoes (Maricopa County Vector Control 2021), many private companies are available that offer mosquito control services. However, since these companies require a fee, pest control measures such as these may be more likely to be used by wealthy individuals [105]. Studies of mosquito populations from the Baltimore area also identify correlations between mosquito abundance and income with lower income neighborhoods containing more mosquitoes [16]. Finally, in the Phoenix Metropolitan Area, higher incomes may also be associated with gated neighborhoods controlled by homeowners' associations. These neighborhoods typically regulate the amount of garbage-potential breeding habitat for mosquitoes - through the collection of trash and limiting public access which may reduce the dumping of garbage [106].

In addition to income features, two demographic variables influenced the perception of mosquitoes as a problem in this study. The two associated variables, age and education, may be linked to lifestyles as well as exposure and perceived risks of mosquitoes. Read et al. [107] found that factors such as how long an individual planned to be outside and whether they used insect repellent were more likely to influence the perception of mosquitoes as annoying than the actual number of mosquitoes collected around an individual. If mosquitoes were seen as more of a health concern for the elderly, we would expect to find that older people had heightened perceptions of mosquitoes as a problem. Our results showed the opposite, suggesting that reduced exposure and time spent outdoors may have been more important drivers of mosquito perceptions than health risks. Consistently, younger individuals often have more free time and use outdoor spaces more often [108,109] and therefore may be more likely to encounter mosquitoes and therefore report them as a problem. Older individuals may also spend more time indoors to avoid heat given their increased risk for heat stress [110,111].

Education's influence on perceptions of mosquitoes as a problem may relate to the potential link between education and knowledge of mosquito-borne disease, though more research could more deeply examine this trend. The public, for example, may tend to view mosquitoes as a health risk in developing countries, particularly in the global South and Africa or other areas where malaria risks are high [30,51]. Yet, in Phoenix, mosquitoes carry several diseases which Maricopa County Vector Control actively tracks, including Dengue and Zika (Maricopa County Vector Control 2021). Our findings suggest that more educated people perceive lower risks, perhaps because they feel more comfortable around mosquitoes [112]. This could be due to a greater awareness of their ability to control mosquito bites and associated threats. However, additional research directly assessing education's impact on the perceptions of mosquitos is needed, especially since general education may not correlate with knowledge of mosquitoes. Formal education may be a poor proxy for awareness of mosquitoes' life history and breeding behaviors since this specific knowledge varies widely among people $[113,114]$. The knowledge that mosquitoes breed in areas such as wetlands as well as areas of natural vegetation or in trash and refuse that may be in vacant lots could drive the association between these features and perceptions of mosquitoes as a problem. For natural vegetation, vacant lots, and desert parks, the influence of these features on perceptions of mosquitoes as a problem diminished distance exceeded $1 \mathrm{~km}$, which roughly matches the potential flight range of a mosquito. This finding may indicate that residents can accurately assess the influence of these landscape features on mosquito populations. However, for wetlands, the influence on the perception of mosquitoes as a problem did not decrease until distances greater than $2 \mathrm{~km}$. In these cases, the link between wetlands and mosquitoes as a problem may have captured a more generalized negative view of wetlands and the idea that wetlands may attract unwanted nuisance animals [57,100].

People's perceptions of their neighborhoods as messy looking were one of the strongest predictors of whether they report mosquitoes as problematic. In many urban environments, 
trash and waste provide breeding grounds for mosquitoes and increase the mosquito population $[16,23]$. Individuals may associate messy-looking neighborhoods with these potential breeding grounds regardless of mosquito abundance or activities. Due to the extreme temperatures in Phoenix, standing water in small pools often evaporates too quickly for mosquitoes to propagate, so trash such as tires that provide reproductive opportunities for mosquitoes in other areas of the world may not be viable $[16,115]$. However, the presence of potential breeding grounds may be enough for individuals to report mosquitoes as problematic. In a 2020 conversation with Maricopa County Vector Control, an agent explained that even after bodies of water, such as ponds, are treated for mosquitoes and the number of captured mosquitoes decreases, Vector Control often continues to receive calls about the body of water as a source of mosquitoes. This mismatch highlights a potentially important element of mosquito management that may need to go beyond reducing mosquito populations.

Understanding how the public reacts to mosquito control may provide managers an opportunity to increase public buy-in and support of disease control. Support for mosquito population management varies by management type (i.e., chemical spraying vs. biological controls; $[45,46]$. Additionally, the support for mosquito control may also vary between regions and different demographics depending on the prevalence and perceptions of mosquito-borne disease $[30,100,113]$. However, one goal of mosquito control is creating environments that are more hospitable to people, either by reducing disease risk or simply reducing annoyances caused by mosquito bites [113,116]. If individuals think that their neighborhood may have a high mosquito abundance, they may spend less time outdoors and therefore be less satisfied with their neighborhood or life in general. Efforts such as community clean-ups have been shown to increase resident perceptions of their neighborhoods and this work shows it may also reduce the perception of mosquitoes as problematic $[84,116]$. Finally, efforts to reduce perceptions of mosquitoes as a problem may also result in more cost-effective vector management. Many vector control agencies respond directly to calls from individuals about complaints and, as a result, may end up treating areas where mosquito risk is low, but the perception of risk is high. Vector management practices could potentially become more efficient by reducing the perception of mosquitoes as problematic, which may reduce unnecessary complaint calls.

\section{Conclusions}

Increasing the effectiveness of managing mosquitoes, and therefore vector-borne diseases, is dire as the climate continues to change, and a growing amount of the global population, increasingly in cities, will be susceptible to disease transmission. The support for social variables, in particular perceptions of neighborhoods, highlights the importance of investigating socioecological dynamics in relation to management of vector-borne diseases. Such understanding of people's perceptions of mosquito abundance may allow for better management practices of mosquito populations. Discerning actual mosquito presence from perceived mosquito presence can allow for more efficient allocation of resources to remove mosquitoes, and an increased understanding of public opinions and can potentially inform effective communication strategies to gather public support for mosquito control practices.

Author Contributions: Conceptualization, J.A.B., K.L.L. and S.J.H.; Methodology, J.A.B., S.B.L. and S.J.H.; Validation: J.A.B., S.B.L., K.L.L. and S.J.H.; Formal analysis, J.A.B.; Data curation, J.A.B.; Investigation, J.A.B. and S.J.H.; Visualization, J.A.B.; Writing-original draft, J.A.B.; Writing-review \& editing, J.A.B., K.L.L., S.B.L., A.C. and S.J.H. Funding acquisition, S.J.H. All authors have read and agreed to the published version of the manuscript.

Funding: This research was funded by the National Science Foundation under grant number DEB1832016, Central Arizona-Phoenix Long-Term Ecological Research Probam (CAP LTER). The APC was waived via editorial voucher (f20638fda94771a2).

Institutional Review Board Statement: The studies involving human participants were reviewed and approved by Arizona State University (ID: 662) IRB-Social \& Behavioral Research Group. 
Informed Consent Statement: The patients/participants provided their written informed consent to participate in this study.

Data Availability Statement: All data analyzed in this study is publicly available and can be found at the CAP LTER data portal (https: / / data.sustainability.asu.edu/cap-portal/home.jsp, accessed on 13 September 2021) or via requesting environmental service data from Maricopa County, Arizona, United States (https:/ / www.maricopa.gov/4214/Public-Records\#12, accessed on 13 September 2021).

Acknowledgments: We would like to acknowledge Maricopa County Vector Control and specifically, Dan Damian, for their expert knowledge and for their help accessing vector control data.

Conflicts of Interest: The authors declare that the research was conducted in the absence of any commercial or financial relationships that could be construed as a potential conflict of interest.

\section{Appendix A}

Table A1. All variables from the boosted regression tree with their relative influence as well as how the variable is measure.

\begin{tabular}{ccc}
\hline Variable & Relative Influence & Variable Measurement \\
\hline Age & 12.4 & Reported Age (Continuous) \\
Km ${ }^{2}$ (continuous) \\
Amount of Natural Vegetation & 12.3 & Likert (1-5) Disagree to Agree \\
Messy Looking Landscape & 11.4 & Km (continuous) \\
Distance from Wetlands & 10.1 & Km (continuous) \\
Distance to Agriculture & 8.8 & $\mathrm{Km}^{2}$ (continuous) \\
Amount of Vacant Land & 8.1 & Count (Continuous) \\
Number of Mosquitoes (log) & 7.2 & Likert-Like (1-11) Increasing \\
Income & 5.7 & Likert-Like (1-7) Low to High Levels of Education \\
Education & 5.1 & Likert (1-5) Disagree to Agree \\
Local Landscape Flooding & 4.8 & Km (continuous) \\
Distance to Water & 4.5 & Km (continuous) \\
Distance to Desert Parks & 4.3 & Binary (female or male) \\
Gender & 2.2 & Binary (no or yes) \\
LatinX & 2.1 & Likert (1-5) Disagree to Agree \\
\hline
\end{tabular}

\section{References}

1. Gubler, D.J. The Global Emergence/Resurgence of Arboviral Diseases As Public Health Problems. Arch. Med. Res. 2002, 33, 330-342. [CrossRef]

2. Wilcox, B.A.; Colwell, R.R. Emerging and Reemerging Infectious Diseases: Biocomplexity as an Interdisciplinary Paradigm. EcoHealth 2005, 2, 244. [CrossRef]

3. Woolhouse, M.E.J.; Gowtage-Sequeria, S. Host Range and Emerging and Reemerging Pathogens. Emerg. Infect. Dis. 2005, 11, 1842-1847. [CrossRef] [PubMed]

4. Morens, D.M.; Fauci, A.S. Dengue and Hemorrhagic FeverA Potential Threat to Public Health in the United States. JAMA 2008, 299, 214-216. [CrossRef] [PubMed]

5. Grandadam, M.; Caro, V.; Plumet, S.; Thiberge, J.-M.; Souarès, Y.; Failloux, A.-B.; Tolou, H.J.; Budelot, M.; Cosserat, D.; Leparc-Goffart, I.; et al. Chikungunya Virus, Southeastern France. Emerg. Infect. Dis. 2011, 17, 910-913. [CrossRef] [PubMed]

6. Healy, K.; Hamilton, G.; Crepeau, T.; Healy, S.; Unlu, I.; Farajollahi, A.; Fonseca, D.M. Integrating the Public in Mosquito Management: Active Education by Community Peers Can Lead to Significant Reduction in Peridomestic Container Mosquito Habitats. PLoS ONE 2014, 9, e108504. [CrossRef]

7. Gubler, D.J. Dengue and Dengue Hemorrhagic Fever. Clin. Microbiol. Rev. 1998, 11, 480-496. [CrossRef]

8. Patterson, G. The Mosquito Wars: A History of Control in Florida; University Press of Florida: Gainesville, FL, USA, 2004.

9. Lopes, G.; Reis-Castro, L. A Vector in the (Re)Making: A History of Aedes aegypti as Mosquitoes that Transmit Diseases in Brazil. In Framing Animals as Epidemic Villains: Histories of Non-Human Disease Vectors; Lynteris, C., Ed.; Medicine and Biomedical Sciences in Modern History; Springer: Cham, Switzerland, 2019; pp. 147-175. ISBN 978-3-030-26795-7.

10. Rochlin, I.; Dempsey, M.E.; Iwanejko, T.; Ninivaggi, D.V. Aquatic Insects of New York Salt Marsh Associated with Mosquito Larval Habitat and Their Potential Utility as Bioindicators. J. Insect Sci. 2011, 11, 172. [CrossRef]

11. Samy, A.M.; Elaagip, A.H.; Kenawy, M.A.; Ayres, C.F.J.; Peterson, A.T.; Soliman, D.E. Climate Change Influences on the Global Potential Distribution of the Mosquito Culex Quinquefasciatus, Vector of West Nile Virus and Lymphatic Filariasis. PLoS ONE 2016, 11, e0163863. [CrossRef] 
12. Nguyen-Tien, T.; Lundkvist, Å.; Lindahl, J. Urban Transmission of Mosquito-Borne Flaviviruses-A Review of the Risk for Humans in Vietnam. Infect. Ecol. Epidemiol. 2019, 9, 1660129. [CrossRef]

13. Mariconti, M.; Obadia, T.; Mousson, L.; Malacrida, A.; Gasperi, G.; Failloux, A.-B.; Yen, P.-S. Estimating the Risk of Arbovirus Transmission in Southern Europe Using Vector Competence Data. Sci. Rep. 2019, 9, 17852. [CrossRef]

14. Sutherst, R.W. Pest Species Distribution Modelling: Origins and Lessons from History. Biol. Invasions 2014, 16, 239-256. [CrossRef]

15. Pickett, S.T.A.; Cadenasso, M.L.; Grove, J.M.; Boone, C.G.; Groffman, P.M.; Irwin, E.; Kaushal, S.S.; Marshall, V.; McGrath, B.P.; Nilon, C.H.; et al. Urban Ecological Systems: Scientific Foundations and a Decade of Progress. J. Environ. Manag. 2011, 92, 331-362. [CrossRef]

16. LaDeau, S.L.; Leisnham, P.T.; Biehler, D.; Bodner, D. Higher Mosquito Production in Low-Income Neighborhoods of Baltimore and Washington, DC: Understanding Ecological Drivers and Mosquito-Borne Disease Risk in Temperate Cities. Int. J. Environ. Res. Public Health 2013, 10, 1505-1526. [CrossRef]

17. Fritz, M.L.; Walker, E.D.; Miller, J.R.; Severson, D.W.; Dworkin, I. Divergent Host Preferences of Above- and below-Ground Culex Pipiens Mosquitoes and Their Hybrid Offspring. Med. Vet. Entomol. 2015, 29, 115-123. [CrossRef]

18. Romeo-Aznar, V.; Paul, R.; Telle, O.; Pascual, M. Mosquito-Borne Transmission in Urban Landscapes: The Missing Link between Vector Abundance and Human Density. Proc. R. Soc. B Biol. Sci. 2018, 285, 826. [CrossRef]

19. Schmidt, N.D.V.; Kovach, T.; Kilpatrick, A.M.; Oviedo, J.L.; Huntsinger, L.; Hruska, T.; Miller, N.L.; Beissinger, S.R. Integrating Social and Ecological Data to Model Metapopulation Dynamics in Coupled Human and Natural Systems. Ecology 2019, 100, e02711. [CrossRef] [PubMed]

20. Goodman, H.; Egizi, A.; Fonseca, D.M.; Leisnham, P.T.; LaDeau, S.L. Primary Blood-Hosts of Mosquitoes Are Influenced by Social and Ecological Conditions in a Complex Urban Landscape. Parasites Vectors 2018, 11, 218. [CrossRef] [PubMed]

21. Okogun, G.R.A.; Anosike, J.C.; Okere, A.; Nwoke, B.; Esekhegbe, A. Epidemiological Implications of Preferences of Breeding Sites of Mosquito Speciesin Midwestern Nigeria. Ann. Agric. Environ. Med. 2003, 10, 217-222. [PubMed]

22. Becker, B.; Leisnham, P.T.; LaDeau, S.L. A Tale of Two City Blocks: Differences in Immature and Adult Mosquito Abundances between Socioeconomically Different Urban Blocks in Baltimore (Maryland, USA). Int. J. Environ. Res. Public Health 2014, 11, 3256-3270. [CrossRef] [PubMed]

23. Wilke, A.B.B.; Beier, J.C.; Benelli, G. Filariasis Vector Control Down-Played Due to the Belief the Drugs Will Be Enough-Not True! Entomol. Gen. 2020, 40, 15-24. [CrossRef]

24. Larson, E.K.; Grimm, N.; Gober, P.; Redman, C. The Paradoxical Ecology and Management of Water in the Phoenix, USA Metropolitan Area. Ecohydrol. Hydrobiol. 2005, 5, 287-296.

25. Keating, J.; Macintyre, K.; Mbogo, C.M.; Githure, J.I.; Beier, J.C. Characterization of Potential Larval Habitats for Anophelesmosquitoes in Relation to Urban Land-Use in Malindi, Kenya. Int. J. Health Geogr. 2004, 3, 9. [CrossRef]

26. Townroe, S.; Callaghan, A. British Container Breeding Mosquitoes: The Impact of Urbanisation and Climate Change on Community Composition and Phenology. PLoS ONE 2014, 9, e95325. [CrossRef]

27. Akhtar, R.; Gupta, P.T.; Srivastava, A.K. Urbanization, Urban Heat Island Effects and Dengue Outbreak in Delhi. In Climate Change and Human Health Scenario in South and Southeast Asia; Akhtar, R., Ed.; Advances in Asian Human-Environmental Research; Springer: Cham, Switzerland, 2016; pp. 99-111, ISBN 978-3-319-23684-1.

28. Armstrong, P.M.; Andreadis, T.G.; Shepard, J.J.; Thomas, M.C. Northern Range Expansion of the Asian Tiger Mosquito (Aedes Albopictus): Analysis of Mosquito Data from Connecticut, USA. PLoS Negl. Trop. Dis. 2017, 11, e0005623. [CrossRef]

29. Thuilliez, J.; Bellia, C.; Dehecq, J.-S.; Reilhes, O. Household-Level Expenditure on Protective Measures Against Mosquitoes on the Island of La Réunion, France. PLoS Negl. Trop. Dis. 2014, 8, e2609. [CrossRef] [PubMed]

30. Gaillard, B.; Simard, F.; Dormont, L.; Jay-Robert, P.; de Lurbe, D.D.; Etienne, M.; Baudin, A.; Raude, J. Is Perceived Exposure to Mosquitoes Associated with Actual Exposure? Results from Studies in High-Risk and Low-Risk Geographic Areas. Am. J. Trop. Med. Hyg. 2019, 101, 976-979. [CrossRef]

31. Murindahabi, M.M.; Takken, W.; Misago, X.; Niyituma, E.; Umupfasoni, J.; Hakizimana, E.; van Vliet, A.J.H.; Poortvliet, P.M.; Mutesa, L.; Murindahabi, N.K.; et al. Monitoring Mosquito Nuisance for the Development of a Citizen Science Approach for Malaria Vector Surveillance in Rwanda. Malar. J. 2021, 20, 36. [CrossRef] [PubMed]

32. Fonseca, D.M.; Unlu, I.; Crepeau, T.; Farajollahi, A.; Healy, S.P.; Bartlett-Healy, K.; Strickman, D.; Gaugler, R.; Hamilton, G.; Kline, D.; et al. Area-Wide Management of Aedes Albopictus. Part 2: Gauging the Efficacy of Traditional Integrated Pest Control Measures against Urban Container Mosquitoes. Pest. Manag. Sci. 2013, 69, 1351-1361. [CrossRef] [PubMed]

33. Unlu, I.; Farajollahi, A.; Strickman, D.; Fonseca, D.M. Crouching Tiger, Hidden Trouble: Urban Sources of Aedes Albopictus (Diptera: Culicidae) Refractory to Source-Reduction. PLoS ONE 2013, 8, e77999. [CrossRef] [PubMed]

34. Rose, R.I. Pesticides and Public Health: Integrated Methods of Mosquito Management. Emerg. Infect. Dis. 2001, 7, 17-23. [CrossRef] [PubMed]

35. Benelli, G.; Maggi, F.; Pavela, R.; Murugan, K.; Govindarajan, M.; Vaseeharan, B.; Petrelli, R.; Cappellacci, L.; Kumar, S.; Hofer, A.; et al. Mosquito Control with Green Nanopesticides: Towards the One Health Approach? A Review of Non-Target Effects. Environ. Sci. Pollut. Res. 2018, 25, 10184-10206. [CrossRef] [PubMed]

36. Baptista, C.; Ong, A. The All-Natural Solution to Mosquito Control. Int. Pest. Control 2010, 52, $215-216$.

37. Kem, W.H. Some Small Native Freshwater Fish Recommended for Mosquito and Midge Control in Ornamental Ponds. EDIS 2005, 2005, 1 . 
38. Scott, T.; Takken, W.; Knols, B.; Boëte, C. The Ecology of Genetically Modified Mosquitoes. Science 2002, 298, 117-119. [CrossRef]

39. Beisel, U.; Boëte, C. The Flying Public Health Tool: Genetically Modified Mosquitoes and Malaria Control. Sci. Cult. 2013, 22, 38-60. [CrossRef]

40. Mutero, C.M.; Schlodder, D.; Kabatereine, N.; Kramer, R. Integrated Vector Management for Malaria Control in Uganda: Knowledge, Perceptions and Policy Development. Malar. J. 2012, 11, 21. [CrossRef]

41. Hlongwana, K.W.; Mavundza, E.J.; Mohapi, E.P.; Kruger, P.; Urbach, J.; Mukaratirwa, S.; Maharaj, R. Vector-Control Personnel's Knowledge, Perceptions and Practices towards Insecticides Used for Indoor Residual Spraying in Limpopo Province, South Africa. Parasites Vectors 2013, 6, 118. [CrossRef]

42. Brown, Z.S.; Kramer, R.A.; Ocan, D.; Oryema, C. Household Perceptions and Subjective Valuations of Indoor Residual Spraying Programmes to Control Malaria in Northern Uganda. Infect. Dis. Poverty 2016, 5, 100. [CrossRef]

43. Halasa, Y.A.; Shepard, D.S.; Wittenberg, E.; Fonseca, D.M.; Farajollahi, A.; Healy, S.; Gaugler, R.; Strickman, D.; Clark, G.G. Willingness-to-Pay for an Area-Wide Integrated Pest Management Program to Control the Asian Tiger Mosquito in New Jersey. Moco 2012, 28, 225-236. [CrossRef]

44. Duman-Scheel, M.; Eggleson, K.K.; Achee, N.L.; Grieco, J.P.; Hapairai, L.K. Mosquito Control Practices and Perceptions: An Analysis of Economic Stakeholders during the Zika Epidemic in Belize, Central America. PLoS ONE 2018, 13, e0201075. [CrossRef] [PubMed]

45. Lull, R.B.; Akin, H.; Hallman, W.K.; Brossard, D.; Jamieson, K.H. Modeling Risk Perceptions, Benefit Perceptions, and Approval of Releasing Genetically Engineered Mosquitoes as a Response to Zika Virus. Environ. Commun. 2020, 14, 933-953. [CrossRef]

46. Capurro, M.L.; Carvalho, D.O.; Garziera, L.; Pedrosa, C.; Damasceno, I.; Lima, I.; Duarte, B.; Fernandes, J.; Lees, R.S.; Malavasi, A. Description of Social Aspects Surrounding Release of Transgenic Mosquitoes in Brazil. Int. J. Recent Sci. Res. 2016, 4, 10363-10369.

47. Decker, D.J.; Evensen, D.T.N.; Siemer, W.F.; Leong, K.M.; Riley, S.J.; Wild, M.A.; Castle, K.T.; Higgins, C.L. Understanding Risk Perceptions to Enhance Communication about Human-Wildlife Interactions and the Impacts of Zoonotic Disease. ILAR J. 2010, 51, 255-261. [CrossRef] [PubMed]

48. Ghosh, A.; Mukherjee, S.; Dutta, T.; Roy, S.; Mondal, F.B. Community Perceptions Regarding Mosquito Borne Diseases in Some Selected Localitities of Bankura, a Peri-Urban Area of West Bengal, India. J. Mosq. Res. 2013, 3, 54-57. [CrossRef]

49. Jordan, R.C.; Sorensen, A.E.; Ladeau, S. Citizen Science as a Tool for Mosquito Control. Moco 2017, 33, 241-245. [CrossRef]

50. Richards, S.L.; Balanay, J.A.G.; Byrd, B.D.; Reiskind, M.H.; Styers, D.M. Regional Survey of Mosquito Control Knowledge and Usage In North Carolina. Moco 2017, 33, 331-339. [CrossRef]

51. Kumar, K.R.; Gururaj, G. Community Perception Regarding Mosquito-Borne Diseases in Karnataka State, India. J. Mosq. Res. $2005,29,8$.

52. Hutchinson, R.; Lindsay, S. Perceived Nuisance of Mosquitoes on the Isle of Sheppey, Kent, UK. J. Biosoc. Sci. 2006, 38, 707-712. [CrossRef]

53. Onwujekwe, O.; Hanson, K.; Fox-Rushby, J. Inequalities in Purchase of Mosquito Nets and Willingness to Pay for InsecticideTreated Nets in Nigeria: Challenges for Malaria Control Interventions. Malar. J. 2004, 3, 6. [CrossRef]

54. Dickinson, K.; Paskewitz, S. Willingness to Pay for Mosquito Control: How Important Is West Nile Virus Risk Compared to the Nuisance of Mosquitoes? Vector-Borne Zoonotic Dis. 2012, 12, 886-892. [CrossRef]

55. Manfredo, M.J. Who Cares about Wildlife? In Who Cares about Wildlife? Social Science Concepts for Exploring Human-Wildlife Relationships and Conservation Issues; Manfredo, M.J., Ed.; Springer: New York, NY, USA, 2008; pp. 1-27. ISBN 978-0-387-77040-6.

56. Kretser, H.E.; Curtis, P.D.; Francis, J.D.; Pendall, R.J.; Knuth, B.A. Factors Affecting Perceptions of Human-Wildlife Interactions in Residential Areas of Northern New York and Implications for Conservation. Hum. Dimens. Wildl. 2009, 14, 102-118. [CrossRef]

57. Brown, J.A.; Larson, K.L.; Lerman, S.B.; Childers, D.L.; Andrade, R.; Bateman, H.L.; Hall, S.J.; Warren, P.S.; York, A.M. Influences of Environmental and Social Factors on Perceived Bio-Cultural Services and Disservices. Front. Ecol. Evol. 2020, 8. [CrossRef]

58. Foley, E.W.; Morreale, R.L.; Hoel, D.F.; Lloyd, A.M. Area-Wide Mosquito Management in Lee County, Florida, USA. In Area-Wide Integrated Pest Management; CRC Press: Boca Raton, FL, USA, 2020; ISBN 978-1-00-316923-9.

59. Trimble, M. Arizoniana: Stories from Old Arizona; Golden West Publishers: Phoenix, AZ, USA, 2002.

60. Kane, K.; York, A.M. Prices, Policies, and Place: What Drives Greenfield Development? Land Use Policy 2017, 68, 415-428. [CrossRef]

61. Larson, K.L.; Gustafson, A.; Hirt, P. Insatiable Thirst and a Finite Supply: An Assessment of Municipal Water-Conservation Policy in Greater Phoenix, Arizona, 1980-2007. J. Policy Hist. 2009, 21, 107-137. [CrossRef]

62. Larson, E.K.; Grimm, N.B. Small-Scale and Extensive Hydrogeomorphic Modification and Water Redistribution in a Desert City and Implications for Regional Nitrogen Removal. Urban. Ecosyst. 2012, 15, 71-85. [CrossRef]

63. Martin, C.A. Landscape Water Use in Phoenix, Arizona. In CALS Publications Archive; The University of Arizona: Tucson, AZ, USA, 2015.

64. Childers, D.L.; Bois, P.; Hartnett, H.E.; McPhearson, T.; Metson, G.S.; Sanchez, C.A. Urban Ecological Infrastructure: An Inclusive Concept for the Non-Built Urban Environment. Elem. Sci. Anthr. 2019, 7, 46. [CrossRef]

65. Shaw, I.G.R.; Robbins, P.F.; Jones, J.P. A Bug's Life and the Spatial Ontologies of Mosquito Management. Ann. Assoc. Am. Geogr. 2010, 100, 373-392. [CrossRef]

66. Kunzweiler, C. West Nile Virus in Maricopa County, Arizona: Investigating Human, Vector, and Environmental Interactions; Arizona State University: Tucson, AZ, USA, 2013. 
67. Hemme, R.R.; Thomas, C.L.; Chadee, D.D.; Severson, D.W. Influence of Urban Landscapes on Population Dynamics in a Short-Distance Migrant Mosquito: Evidence for the Dengue Vector Aedes Aegypti. PLoS Negl. Trop. Dis. 2010, 4, e634. [CrossRef]

68. Tsuda, Y.; Komagata, O.; Kasai, S.; Hayashi, T.; Nihei, N.; Saito, K.; Mizutani, M.; Kunida, M.; Yoshida, M.; Kobayashi, M. A Mark-Release-Recapture Study on Dispersal and Flight Distance of Culex Pipiens Pallens in an Urban Area of Japan. Moco 2008, 24, 339-343. [CrossRef]

69. Larson, K.; York, A.; Andrade, R.; Wittlinger, S. Phoenix Area Social Survey (PASS): 2017; Arizona State University: Tucson, AZ, USA, 2020.

70. Verdonschot, P.F.M.; Besse-Lototskaya, A.A. Flight Distance of Mosquitoes (Culicidae): A Metadata Analysis to Support the Management of Barrier Zones around Rewetted and Newly Constructed Wetlands. Limnologica 2014, 45, 69-79. [CrossRef]

71. Brown, J.; Larson, K.; Lerman, S.; Childers, D.; Andrade, R.; Bateman, H.; Hall, S.; Warren, P.; York, A. Urban Ecological Infrastructure (UEI) in the Greater Phoenix, Arizona Metropolitan Area and Surrounding Sonoran Desert Region (2010-2017); Arizona State University: Tucson, AZ, USA, 2021.

72. Zhang, Y.; Li, X. Land Cover Classifications of CAP LTER Study Area at Five-Year Intervals; Central Arizona-Phoenix Long-Term Ecological Research, Arizona State University: Tucson, AZ, USA, 2017.

73. Yang, L.; Jin, S.; Danielson, P.; Homer, C.; Gass, L.; Bender, S.M.; Case, A.; Costello, C.; Dewitz, J.; Fry, J.; et al. A New Generation of the United States National Land Cover Database: Requirements, Research Priorities, Design, and Implementation Strategies. ISPRS J. Photogramm. Remote Sens. 2018, 146, 108-123. [CrossRef]

74. Smith, J.P.; Li, X.; Turner, B.L. Lots for Greening: Identification of Metropolitan Vacant Land and Its Potential Use for Cooling and Agriculture in Phoenix, AZ, USA. Appl. Geogr. 2017, 85, 139-151. [CrossRef]

75. Matthys, B.; N’Goran, E.K.; Koné, M.; Koudou, B.G.; Vounatsou, P.; Cissé, G.; Tschannen, A.B.; Tanner, M.; Utzinger, J. Urban Agricultural Land Use and Characterization of Mosquito Larval Habitats in a Medium-Sized Town of Côte d'Ivoire. J. Vector Ecol. 2006, 31, 319-333. [CrossRef]

76. Yadav, P.; Foster, W.A.; Mitsch, W.J.; Grewal, P.S. Factors Affecting Mosquito Populations in Created Wetlands in Urban Landscapes. Urban Ecosyst. 2012, 15, 499-511. [CrossRef]

77. Smith, V.K.; Larson, K.L.; York, A. Using Quality Signaling to Enhance Survey Response Rates. Appl. Econ. Lett. 2020, $27,951-954$. [CrossRef]

78. Murdock, C.C.; Evans, M.V.; McClanahan, T.D.; Miazgowicz, K.L.; Tesla, B. Fine-Scale Variation in Microclimate across an Urban Landscape Shapes Variation in Mosquito Population Dynamics and the Potential of Aedes Albopictus to Transmit Arboviral Disease. PLoS Negl. Trop. Dis. 2017, 11, e0005640. [CrossRef] [PubMed]

79. Slovic, P. The Feeling of Risk: New Perspectives on Risk Perception; Routledge: London, UK, 2010; ISBN 978-1-84971-149-4.

80. Wai, K.T. Gender, Mosquitos and Malaria: Implications for Community Development Programs in Laputta, Myanmar. Southeast. Asian J. Trop. Med. Public Health 2001, 32, 588-894.

81. Sreetheran, M.; van den Bosch, C.C.K. A Socio-Ecological Exploration of Fear of Crime in Urban Green Spaces-A Systematic Review. Urban For. Urban Green. 2014, 13, 1-18. [CrossRef]

82. Larson, K.L.; Ibes, D.C.; White, D.D. Gendered Perspectives about Water Risks and Policy Strategies: A Tripartite Conceptual Approach. Environ. Behav. 2011, 43, 415-438. [CrossRef]

83. Avolio, M.; Blanchette, A.; Sonti, N.F.; Locke, D.H. Time Is Not Money: Income Is More Important Than Lifestage for Explaining Patterns of Residential Yard Plant Community Structure and Diversity in Baltimore. Front. Ecol. Evol. 2020, 8, 85. [CrossRef]

84. Yasuoka, J.; Mangione, T.W.; Spielman, A.; Levins, R. Impact of Education on Knowledge, Agricultural Practices, and Community Actions for Mosquito Control and Mosquito-Borne Disease Prevention in Rice Ecosystems in Sri Lanka. Am. J. Trop. Med. Hyg. 2006, 74, 1034-1042. [CrossRef]

85. Reyburn, H.; Mbatia, R.; Drakeley, C.; Bruce, J.; Carneiro, I.; Olomi, R.; Cox, J.; Nkya, W.M.M.M.; Lemnge, M.; Greenwood, B.M.; et al. Association of Transmission Intensity and Age with Clinical Manifestations and Case Fatality of Severe Plasmodium Falciparum Malaria. JAMA 2005, 293, 1461-1470. [CrossRef]

86. Zielinski-Gutierrez, E.C.; Hayden, M.H. A Model for Defining West Nile Virus Risk Perception Based on Ecology and Proximity. EcoHealth 2006, 3, 28-34. [CrossRef]

87. McCullagh, P.; Nelder, J.A. Generalized Linear Models, 2nd ed.; Routledge: Boca Raton, FL, USA, 2019; ISBN 978-0-203-75373-6.

88. Hastie, T.; Tibshirani, R. Varying-Coefficient Models. J. R. Stat. Soc. Ser. B 1993, 55, 757-779. [CrossRef]

89. Elith, J.; Leathwick, J.R.; Hastie, T. A Working Guide to Boosted Regression Trees. J. Anim. Ecol. 2008, 77, 802-813. [CrossRef]

90. De'ath, G. Boosted Trees for Ecological Modeling and Prediction. Ecology 2007, 88, 243-251. [CrossRef]

91. Breiman, L. Random Forests. Mach. Learn. 2001, 45, 5-32. [CrossRef]

92. Greenwell, B.; Boehmke, B.; Cunningham, J. Package “Gmb”. Available online: https://cran.r-project.org/web/packages/gbm/ gbm.pdf (accessed on 1 May 2021).

93. Shwartz, A.; Turbé, A.; Simon, L.; Julliard, R. Enhancing Urban Biodiversity and Its Influence on City-Dwellers: An Experiment. Biol. Conserv. 2014, 171, 82-90. [CrossRef]

94. Pett, T.J.; Shwartz, A.; Irvine, K.N.; Dallimer, M.; Davies, Z.G. Unpacking the People-Biodiversity Paradox: A Conceptual Framework. BioScience 2016, 66, 576-583. [CrossRef]

95. Slovic, P. Perception of Risk. Science 1987, 236, 280-285. [CrossRef] 
96. Brown, H.; Diuk-Wasser, M.; Andreadis, T.; Fish, D. Remotely-Sensed Vegetation Indices Identify Mosquito Clusters of West Nile Virus Vectors in an Urban Landscape in the Northeastern United States. Vector-Borne Zoonotic Dis. 2008, 8, 197-206. [CrossRef] [PubMed]

97. Yang, L.; Turo, K.J.; Riley, C.B.; Inocente, E.A.; Tian, J.; Hoekstra, N.C.; Piermarini, P.M.; Gardiner, M.M. Can Urban Greening Increase Vector Abundance in Cities? The Impact of Mowing, Local Vegetation, and Landscape Composition on Adult Mosquito Populations. Urban Ecosyst. 2019, 22, 827-839. [CrossRef]

98. Elwell, T.L.; Gelcich, S.; Gaines, S.D.; López-Carr, D. Using People's Perceptions of Ecosystem Services to Guide Modeling and Management Efforts. Sci. Total Environ. 2018, 637-638, 1014-1025. [CrossRef]

99. Lincoln, N.K.; Ardoin, N.M. Cultivating Values: Environmental Values and Sense of Place as Correlates of Sustainable Agricultural Practices. Agric. Hum. Values 2016, 33, 389-401. [CrossRef]

100. Cottet, M.; Piégay, H.; Bornette, G. Does Human Perception of Wetland Aesthetics and Healthiness Relate to Ecological Functioning? J. Environ. Manag. 2013, 128, 1012-1022. [CrossRef]

101. Thomson, J.S.; Kelvin, R.E. Suburbanites' Perceptions About Agriculture: The Challenge for Media. J. Appl. Commun. 1996, 80, 1339. [CrossRef]

102. Gouge, D.H.; Li, S.; Walker, K.; Sumner, C.; Nair, S.; Olson, C. Mosquitoes: Biology and Integrated Mosquito Management. In CALS Publications Archive; The University of Arizona: Tucson, AZ, USA, 2016.

103. Hayden, M.H.; Uejio, C.K.; Walker, K.; Ramberg, F.; Moreno, R.; Rosales, C.; Gameros, M.; Mearns, L.O.; Zielinski-Gutierrez, E.; Janes, C.R. Microclimate and Human Factors in the Divergent Ecology of Aedes Aegypti along the Arizona, U.S./Sonora, MX Border. EcoHealth 2010, 7, 64-77. [CrossRef]

104. Chapter 37 Water. Article 1. In General. Sec. 37-27. Waste of Water; Failure of Consumer to Make Repairs to Pipes, Valves, and Fixtures; Municipal Codes of Ordinance: Phoenix, AZ, USA, 2016.

105. Bateman, H.L.; Brown, J.A.; Larson, K.L.; Andrade, R.; Hughes, B. Unwanted Residential Wildlife: Evaluating Social-Ecological Patterns for Snake Removals. Glob. Ecol. Conserv. 2021, 27, e01601. [CrossRef]

106. McKenzie, E. Homeowner Associations and California Politics: An Exploratory Analysis. Urban Aff. Rev. 1998, $34,52-75$. [CrossRef]

107. Read, N.R.; Rookert, J.R. Public Perception of MOsquito Annoyance Measured by a Survey and Simultaneous Mosquito Sampling. J. Am. Mosq. Control Assoc. 1994, 10, 79-87.

108. Goerres, A. Why Are Older People More Likely to Vote? The Impact of Ageing on Electoral Turnout in Europe. Br. J. Polit. Int. Relat. 2007, 9, 90-121. [CrossRef]

109. Godbey, G.; Blazey, M. Old People in Urban Parks: An Exploratory Investigation. J. Leis. Res. 1983, 15, 229-244. [CrossRef]

110. Sheridan, S.C. A Survey of Public Perception and Response to Heat Warnings across Four North American Cities: An Evaluation of Municipal Effectiveness. Int J. Biometeorol. 2007, 52, 3-15. [CrossRef] [PubMed]

111. Hondula, D.M.; Davis, R.E.; Leisten, M.J.; Saha, M.V.; Veazey, L.M.; Wegner, C.R. Fine-Scale Spatial Variability of Heat-Related Mortality in Philadelphia County, USA, from 1983-2008: A Case-Series Analysis. Environ. Health 2012, 11, 16. [CrossRef] [PubMed]

112. Dike, N.; Onwujekwe, O.; Ojukwu, J.; Ikeme, A.; Uzochukwu, B.; Shu, E. Influence of Education and Knowledge on Perceptions and Practices to Control Malaria in Southeast Niger. Soc. Sci. Med. 2006, 63, 103-106. [CrossRef]

113. Patel, A.; Rathod, H.; Shah, P.; Garsondiya, J.; Sharma, R. Perceptions Regarding Mosquito Borne Diseases in an Urban Area of Rajkot City. Natl. J. Med. Res. 2011, 1, 45-47.

114. Morse, W.; Izenour, K.; McKenzie, B.; Lessard, S.; Zohdy, S. Perceptions and Practices of Mosquito-Borne Diseases in Alabama-Is Concern Where It Should Be? BMC Public Health 2019, 19, 987. [CrossRef]

115. McGinley, S. This Mosquito Loves Tucson: Monsoon Conditions Support Carrier of Dengue Fever. Univ. Ariz. Univ. Libr. 2001, 1, $1-3$.

116. Leslie, T.E.; Carson, M.; van Coeverden, E.; Klein, K.D.; Braks, M.; Krumeich, A. An Analysis of Community Perceptions of Mosquito-Borne Disease Control and Prevention in Sint Eustatius, Caribbean Netherlands. Glob. Health Action 2017, 10, 1350394. [CrossRef] 